\title{
(6)
}

\section{A TRANSVERSALIDADE DO ENSINO DA PRÁTICA NA FORMAÇÃO PROFISSIONAL DO ASSISTENTE SOCIAL E O PROJETO ABEPSS ITINERANTE}

\author{
THE TRANSVERSALITY OF TEACHING OF PRACTICE \\ IN SOCIAL WORKER PROFESSIONAL FORMATION \\ AND THE ABEPSS INTINERANT PROJECT
}

\section{Cláudia Mônica dos Santos' Francisca Pini ${ }^{2}$}

\section{RESUMO}

Este artigo tem como objeto a formação profissional do Assistente Social e objetiva explicitar nosso entendimento acerca do ensino da prática e sua relação com o estágio em Serviço Social, apresentando o debate travado no Projeto ABEPSS itinerante, desenvolvido no ano de 2012. Fundamenta-se em três princípios do projeto de formação profissional de 1996, os quais são nossa referência. Divide-se em três partes: a concepção de transversalidade do ensino da prática; o estágio como um dos elementos que compõem o ensino da prática, desmontando a concepção de que ele é o único momento da formação responsável pela relação teoria/prática;como as unidades de formação acadêmica vêm compreendendo o ensino da prática a partir dos debates ocorridos,

1 Assistente Social, doutora pela UFRJ. Professora Associado I da Faculdade de Serviço Social da Universidade Federal de Juiz de Fora. Vice-coordenadora do Programa de Pós-graduação em Serviço Social da FSS/UFJF, gestão 2013-2015. Presidente da ABEPSS Gestão 2011-2012.Email: cmonicasantos@gmail.com

2 Assistente Social, mestre e doutora. Coordenadora licenciada do curso de Serviço Social da Faculdade de Mauá. Diretora pedagógica do Instituto Paulo Freire. Vice-presidente da ABEPSS Regional Gestão Sul II 2011-2012.

Email: franpini@paulofreire.org 
nacionalmente, por ocasião do desenvolvimento do Projeto ABEPSS itinerante.

Palavras-chave: Formação Profissional. Serviço Social. Ensino da prática.

\section{ABSTRACT}

This article focuses on the social worker professional formation and aims to clarify our understanding of teaching of practice and its relationship with the internship in Social Service, presenting the discussion that has happened during the ABEPSS Itinerant Project, developed in the year of 2012. Our exposure is based on three principles that rules our professional formation project, approved in 1996, which is our reference. It is divided into three parts: the conception of transversality of teaching of practice; the internship as one of the elements that constitute this teaching of practice, dismantling the notion that it is the only moment of formation that is responsible for the theory/practice interaction; how units of academic formation has comprehended teaching of practice from the discussions held, across the nation, during the development of the ABEPSS Itinerant Project.

Keywords: Professional Formation. Social Service. Teaching of Practice. Submetido em 01/04/2013

Aceito em 03/06/2013

\section{INTRODUÇÃO}

Este artigo tem por objetivo explicitar nosso entendimento acerca do ensino da prática e sua relação com o estágio em Serviço Social, apresentando o debate surgido durante o módulo I do Projeto ABEPSS itinerante, desenvolvido em todas as regiões da ABEPSS durante o ano de 2012. Nossa exposição fundamenta-se em três princípios que regem nosso projeto de formação profissional aprovado em 1996, bem como, contidos nos princípios do estágio presentes na Política Nacional de Estágio - PNE (ABEPSS, 2010), os quais são nossa referência. Quais sejam:

1. Há uma transversalidade do ensino da prática em nossa proposta de diretrizes curriculares, esta entendida como ensino teórico-prático que envolve diferentes tipos de conhecimentos;

2. O estágio é um dos componentes curriculares desse ensino da prática que dá materialidade ao nosso projeto de formação profissional, ou seja, é um momento privilegiado na relação teoria/ prática; 
3. O estágio supervisionado em Serviço Social tem centralidade nas Diretrizes Curriculares (Estágio obrigatoriamente acompanhado de supervisão acadêmica e de campo).

Desta forma, este artigo foi dividido em três partes. A primeira expõe a nossa concepção de transversalidade do ensino da prática, negando a concepção de uma "suposta" separação entre teoria e prática e afirmando a concepção de que a nossa formação exige diferentes tipos de conhecimentos, dentre eles, o teórico, o procedimental, o cultural. Mas, a despeito disso, todos esses conhecimentos se voltam para o ensino da prática profissional.

A segunda parte traz o estágio como um dos elementos que compõem esse ensino da prática, porém, indo na contramão da concepção de que ele é o único momento da formação responsável pela relação teoria/prática, mas, sim um componente privilegiado por fazer a mediação entre conhecimento teórico e conhecimento procedimental. A terceira e última parte apresenta como as unidades de formação acadêmicas vêm compreendendo essa relaçãoem seus cursos a partir dos debates ocorridos nacionalmente, por ocasião do desenvolvimento do Projeto ABEPSS itinerante.

\section{A TRANSVERSALIDADE DO “ENSINO DA PRÁTICA" NO PROJETO DE FORMAÇÃO PROFISSIONAL DE 1996.}

É comum na academia presenciarmos os estudantes de Serviço Social que estão nos primeiros períodos do curso - antes de ingressarem no estágio -reclamarem que não estão tendo contato com a prática profissional. Queixam-se do excesso de disciplinas teóricas e, indignados, afirmam que "só aprendem teoria e querem aprender como faz Serviço Social” (sic). Ansiosos, reivindicam que o estágio seja transferido para o início do curso ou o ingresso em estágios não obrigatórios: "Querem aprender a prática do Serviço Social e não somente teoria” (sic). De outro modo, ao ingressarem no estágio, reclamam que o que aprenderam nos períodos anteriores não serve para a prática, ou seja, "na prática a teoria é outra”. Essas afirmativas fazem parte da típica ideia de separação entre teoria e prática³.

3 Esse tema foi desenvolvido densamente por Santos (2006; 2010), Forti e Guerra (2010). 
De certa forma, até aproximadamente a década de 1980, a própria academia, no que se refere, também, aos cursos de Serviço Social, reforçava essa concepção ao apresentar os currículos divididos em ciclo básico e ciclo profissionalizante. O ciclo básico compreendia os componentes curriculares de outras áreas, mais do âmbito teórico. Já o ciclo profissionalizante, compreendia os componentes próprios do Serviço Social, dos fundamentos do trabalho profissional e conhecimentos de âmbito operacional, procedimental e/ou técnico-operativos, ou seja, da intervenção profissional do Assistente Social.

Igualmente, na própria historiografia do Serviço Social, quanto ao que se refere à competência profissional, temos, nitidamente, essa separação: no início da profissão, a "competência profissional" era considerada, apenas, como competência técnico-operativa. Na década de 1970/1980, a "competência profissional” resumia-se à competência teórico-política. Foi com o currículo de 1996, aprovado pela categoria em convenção da Associação Brasileira de Ensino em Serviço Social (ABESS), hoje Associação Brasileira de Ensino e Pesquisa em Serviço Social (ABEPSS), que se rompeu com essa separação no projeto de formação profissional. Competência profissional passa a ser vista como competência teórica, política, ética e técnico-operativa.

Essa proposta reconhece, a partir de um referencial teórico marxista, a relação de unidade na diversidade entre teoria e prática. A teoria oferece o conhecimento sobre o objeto a ser estudado e não a sua transformação. Esse objeto, por sua vez, já existe. É parte de uma prática social, e, como tal, só pode ser conhecido ou apreendido em sua essência, a partir de um conhecimento teórico.

Conforme Santos (2010), a teoria, como Marx sustenta, é a reprodução ideal do movimento real do objeto a ser conhecido. Ela é reprodução, reconstituição do objeto pelo pensamento. Ou seja, a produção do mundo concreto dá-se no âmbito da prática, mas a prática pode ser reproduzida no âmbito da razão pelo pensamento. Entretanto, esse processo de investigação não modifica necessariamente o dado, o objeto. O dado, o concreto - produto 
das ações práticas do homem - pode continuar o mesmo no plano empírico, necessitando de mediações para ser modificado.

Nessa perspectiva, a prática é o lugar para o qual o pensamento se volta. Podemos afirmar, então, que teoria e prática constituem uma unidade na diversidade, isto é, são categorias distintas, mas que mantém uma relação visceral entre elas. Não podem ser vistas em separado. Entretanto, a despeito da teoria não se aplicar ao real, ela oferece "parâmetros para uma análise criativa que recupere as especificidades do processo de formação da sociedade nacional, dos movimentos e inflexões conjunturais, dos atores e forças políticas aí presentes" (IAMAMOTO, 1992, p. 179 apud SANTOS, 2010, p. 93).

Assim, para formação de profissionais de nível superior, são necessários vários tipos de conhecimentos, dentre eles, o conhecimento teórico sobre a vida social, sobre a realidade que criou e sustenta essa profissão, ou seja, sobre a prática social em que se deu origem, fortaleceu, alimentou e alimenta essa profissão; sobre os sujeitos que buscam o profissional, bem como, do conhecimento procedimental da profissão, da cultura profissional.

Nessa direção, toda formação é teórico-prática, no sentido de que os conteúdos que tratam da teoria assim o fazem por ser esta uma interpretação da realidade com a qual vamos atuar como profissionais.

Acreditamos que quando os estudantes acusam a formação de "teoricista", na verdade, estão sentindo falta de uma formação que faça a mediação entre os conhecimentos teóricos sobre a vida social e os sujeitos e a intervenção profissional. Ou melhor, sentem falta, nos currículos, de conteúdos que tratam mais especificamente dos conhecimentos procedimentais, fazendo a mediação com os conteúdos teórico-práticos.

Segundo nosso Projeto de Formação Profissional, o ensino da prática encontra-se em toda a formação profissional. Entretanto, há componentes curriculares que se aproximam mais do âmbito da teoria - enquanto apreensão do real pelo pensamento - e outros mais da prática profissional propriamente dita, dos conhecimentos operativos/procedimentais da intervenção. 
Mas, reforçamos que todos os conhecimentos se voltam para a intervenção, na medida em que a formação profissional requisita níveis diferenciados de conhecimentos: teórico, político, ético e procedimental, devendo contemplar todos eles. Isso é fundamental para não se exigir de um determinado tipo de conhecimento aquilo que não é de sua natureza.

Desse modo, o que se reivindica é uma qualificação operativa, que se dá, concomitantemente, com saberes reflexivos e saberes interventivos e, também, uma relação aproximada entre formação e realidade. Entretanto, não podemos desconsiderar o fato de que a realidade é mais dinâmica que a teoria. Portanto, apesar da formação ser um espaço para releitura crítica da realidade, esta última estará sempre à frente. Daí a necessidade da projeção.

A articulação efetiva entre teoria social e prática profissional possibilita ao estudante a intervenção crítica e contribui para o desvelamento das contradições da sociedade capitalista, para os limites e possibilidades do trabalho profissional e para a totalidade da realidade que legitima o exercício profissional do assistente social nos diversos espaços socioinstitucionais.

Assim, não se pode afirmar que há "um lugar" específico do ensino da prática no currículo. Este está contido em todo o processo de formação profissional no sentido de:

- desenvolver uma capacidade de reflexividade, a partir da articulação das três dimensões presentes nos processos de trabalho que os assistentes sociais desenvolvem (teórico-metodológica, ético-política e técnico-operativa), pois articulam interesses e perspectivas distintos, possibilitando a construção de táticas e estratégias;

- o ensino da prática não estar deslocado das particularidades dos processos de trabalho, das formas que a profissão vai assumindo ao longo do tempo, conforme Cassab (2000);

- o ensino da prática supor a dimensão do conhecimento da matéria sobre a qual o Serviço Social atua, dos meios e instrumentos necessários na produção dos resultados (CASSAB, 2000),e também de um conhecimento acerca das condições que 
potencializam ou dificultam seu fazer, além, do horizonte ético-político construído pela categoria profissional.

Portanto, não é possível desvincular o ensino da prática das condições nas quais ele se efetiva, pois essa articulação proporciona, no processo de formação profissional, uma capacidade do estudante de estabelecer sínteses, de desconstruir um pensamento orientado por modelos aplicáveis, de articular crítica e criativamente os diversos elementos que estão presentes em sua formação.

Nessa perspectiva, a formação profissional trabalha com diferentes tipos de conhecimentos,em um processo que envolve as três dimensões da intervenção: Teórico-metodológica, Éticopolítica, Técnico-operativa.

A dimensão Teórico-metodológica nos oferece os conhecimentos que fornecem um ângulo de leitura dos processos sociais, de compreensão do significado social da ação, uma explicação da dinâmica da vida social na sociedade capitalista.

A dimensão Ético-política oferece-nos os conhecimentos do processo de construção de um ethos profissional, o significado de seus valores e as implicações ético-políticas no trabalho profissional. Esses conhecimentos possibilitam projetar a ação em função dos valores e finalidades, avaliar as consequências da ação e tomar posição, tomar partido.

Já a dimensão Técnico-operativa oferece-nos os conhecimentos que permitem executar a ação que se planejou (com base em valores e na análise do real).

Nessa direção,as diretrizes gerais para o curso de Serviço Social estruturaram o currículo em três grandes eixos que articulam um "conjunto de conhecimentos e habilidades necessário à qualificação profissional dos assistentes sociais na atualidade" (ABESS-CEDEPSS, 1997) -conhecimentos teórico, político, artístico, procedimental etc. Não por acaso,esses eixos são considerados como Núcleos de Formação profissional. São eles:

Núcleo de fundamentos teóricos-metodológicos da vida social, que trata dos conteúdos de fundamentos teórico-metodológicos e éticos para o conhecimento do ser social em sua 
totalidade, partindo do trabalho como eixo central do processo de reprodução da vida social. A partir dessa perspectiva, objetiva-se a compreensão da sociedade burguesa e suas contradições.

Núcleo de fundamentos da formação sócio-histórica da sociedade brasileira, que objetiva o conhecimento da formação sócio-histórica do Brasil. Portanto, são objetos de análise: os padrões de produção capitalista; a constituição do Estado brasileiro; o significado do Serviço Social no seu caráter contraditório; os diferentes projetos políticos em disputa; bem como a trajetória, ação e movimento das classes subalternas e o surgimento, a emergência, o desenvolvimento das diferentes refrações da Questão Social.

Núcleo de fundamentos do trabalho profissional, que se volta para conteúdos mais diretamente relacionados ao exercício profissional, inserindo-se nesse núcleo componentes curriculares mais relacionadas à intervenção do assistente social.

Esses núcleos são considerados como indissociáveis entre si em uma relação de horizontalidade entre os mesmos, expressando "níveis diferenciados de apreensão da realidade social e profissional, subsidiando a intervenção do Serviço Social" (ABESS/ CEDEPSS, 1997, p.64). Toda proposta curricular encontra-se estruturada a partir desses núcleos temáticos, ou seja, os componentes curriculares, matérias, disciplinas, atividades complementares e atividades indispensáveis integradoras do currículo devem ser originadas desses núcleos.

Tais núcleos detêm a possibilidade de instrumentalizar o assistente social para a intervenção profissional, sendo que, o núcleo de fundamentos do trabalho profissional é considerado central nas Diretrizes Curriculares e os demais direcionam-se a ele complementando-o e reforçando-o, pois, para uma intervenção com competência, faz-se necessária a compreensão do significado social da profissão.

O eixo de fundamentos do trabalho profissional permite uma maior vinculação da academia com o campo de intervenção do Serviço Social. Isso porque é nesse eixo que se encontram todos os elementos constitutivos da profissão como uma 
especialização do trabalho - trajetória histórica da profissão; as dimensões teórico-metodológicas, ético-políticas, técnico-operativas; a postura investigativa; o estágio supervisionado e o Trabalho de Conclusão de Curso (TCC).

Essa lógica tem como suposto essa relação teoria-prática, como afirma Ivanete Boschetti (2004, p. 29): “o ensino da prática ocorre nos três eixos, os conteúdos devem ter a preocupação de mostrar a vinculação entre teoria, realidade e as possibilidades de intervenção profissional em diferentes contextos e momentos históricos".

Essa estrutura significa que o ensino da prática perpassa todos esses eixos, todos se voltam para a prática profissional do assistente social em suas mais diversas expressões: organizativa, interventiva, investigativa, formativa. Entretanto, como vimos acima, alguns conteúdos são de âmbito mais teórico, outros mais procedimentais, outros culturais, etc. Dessa forma, alguns componentes podem ter como referência um ou outro âmbito, mas, sempre tendo como direção o Serviço Social como profissão interventiva e investigativa. É nessa direção que vamos nos deter a um desses componentes curriculares: o estágio supervisionado em Serviço Social, tendo em vista que, historicamente, ele vem sendo tratado como o único componente curricular que trata do ensino da prática no Serviço Social.

\section{DESMISTIFICANDO O ESTÁGIO SUPERVISIONADO EM SERVIÇO SOCIAL COMO O ÚNICO MOMENTO QUE POSSIBILITA O ENSINO DA PRÁTICA NA FORMAÇÃO PROFISSIONAL.}

O estágio é um dos elementos desse ensino teórico-prático, porém é central nessa proposta. Central, porque envolve princípios fundamentais do nosso Projeto de Formação a saber:

- Articulação entre Formação e Exercício Profissional.

- Indissociabilidade entre estágio e supervisão acadêmica e de campo.

- Articulação entre universidade e sociedade.

- Interdisciplinaridade.

- Articulação entre ensino, pesquisa e extensão e,

- Unidade teoria-prática. 
Ele é um momento especial de nossa aprendizagem por propiciar a relação conhecimento teórico e procedimental, teoria e realidade do mercado de trabalho do assistente social, tendo como fundamento os campos sócio-ocupacionais dos Assistentes Sociais. Isso porque:

$1^{\circ}$ - Ele é um componente curricular que, obrigatoriamente, propicia o contato do estudante e como os elementos constitutivos da realidade profissional, com os fundamentos do Serviço Social e com as expressões da Questão Social. Além disso, esse componente pode contribuir, diretamente, com a aquisição de experiências e, assim, possibilitar a aquisição das habilidades necessárias para os procedimentos interventivos.

$2^{\circ}$ - Ao mesmo tempo, por meio das supervisões (acadêmicas e de campo), possibilita a ampliação de conhecimentos teóricos sobre a realidade, sobre o objeto de nossa intervenção, ou seja, sobre a Questão Social e suas expressões, propiciando uma leitura crítica da realidade. Referimo-nos aqui à articulação necessária entre formação e mercado de trabalho, no qual a profissão se realiza e se reproduz.

Trata-se de entender as demandas postas no mercado de trabalho com a finalidade de empreender um movimento reflexivo sobre tais demandas, a partir de uma referência crítica, buscando a elucidação de impasses e contradições nem sempre aparentes.

Essa perspectiva de vinculação da profissão com a realidade decorre, também, da definição da Questão Social como seu eixo fundamental, pois isso pressupõe "[...] a apreensão da vinculação da profissão com as novas configurações da Questão Social, apreendida no interior do processo de reprodução da relação entre capital e trabalho" (ABESS/CEDEPSS, 1996, p.149).

O estágio deve constituir-se como um processo de ensino-aprendizado, um momento de reflexão, de construção, de consolidação dos diferentes conhecimentos que perfazem o ensino teórico-prático da profissão. Ele extrapola os muros da universidade, sendo considerado um dos elementos que possibilita, também, a imprescindível articulação entre formação e exercício profissional. 
Segundo Santos e Abreu (2012), o estágio, como dimensão central, é um espaço privilegiado na efetivação da relação entre a dimensão teórico-metodológica, ético-política e técnico-operativa. Espaço para aprendizagem do processo de trabalho através da relação teoria-prática como unidade indissolúvel. Nessa direção, são objetivos do estágio:

- Possibilitar experiências que ultrapassem o atendimento exclusivo das novas demandas do mercado de trabalho, ampliando os horizontes com o desenvolvimento de competências técnico-operativas, ético-políticas e teórico-metodológicas.

- Contribuir com uma intervenção crítica, propositiva e investigativa do profissional.

O Estágio é um dos componentes curriculares que envolve exercício e formação profissional, uma vez que se realiza no espaço sócio-ocupacional do assistente social, exigindo o supervisor de campo, além de acompanhamento docente, por meio do supervisor acadêmico.

Pensar o estágio nesse contexto impõe considerar as mudanças no mundo do trabalho contemporâneo e seus rebatimentos para o Serviço Social nas dimensões da intervenção e da formação profissional, bem como situar a supervisão de campo como "atribuição privativa do assistente social”. Exige pensá-lo para além de uma atividade prática.

Enfim, queremos reforçar que o estágio é um momento privilegiado para o desenvolvimento de competências e habilidades para o exercício das atribuições profissionais do assistente social, uma vez que se constitui através da inserção do estudante no espaço socioinstitucional (ABEPSS, 2010). Contudo, não se traduz no único espaço a tratar a intervenção profissional. Nessa direção, a seguir, traçaremos algumas considerações sobre como, hoje, a categoria vem tratando a questão do ensino da prática. 


\title{
REFLEXÕES SOBRE O ENSINO DA PRÁTICA NO PROJETO “ABEPSS ITINERANTE"
}

Na gestão 2011-2012 da ABEPSS, foi desenvolvido o Projeto ABEPSS Itinerante ${ }^{4}$, o qual teve por objetivo geral

\begin{abstract}
fortalecer as estratégias político-pedagógicas de enfrentamento à precarização do ensino superior, por meio da difusão ampla dos princípios, conteúdos e desafios colocados para a consolidação das Diretrizes Curriculares de 1996,como instrumento fundamental na formação de novos profissionais (reforço dos eixos: Fundamentos, Trabalho, Questão Social, Ética, Pesquisa e Ensino da Prática) (ABEPSS, 2012, p. 15).
\end{abstract}

Os critérios para participação nesse projeto foram, prioritariamente, os candidatos serem docentes; supervisores de estágio de campo; participarem de comissões de formação dos CRESS; discentes de pós-graduação stricto sensu (mestrado ou doutorado).

O Projeto foi operacionalizado de acordo com as regiões da ABEPSS e trabalhou os seguintes módulos: Módulo I - Transformações societárias e o projeto de formação profissional do serviço social: desafios para a implantação das Diretrizes Curriculares; Módulo II - O método crítico-dialético e os Fundamentos teórico-metodológicos do Serviço Social na Formação Profissional; Módulo III - Trabalho e Questão social na Formação Profissional; Módulo IV - A Ética profissional na Formação Profissional; Módulo V - Pesquisa na Formação Profissional; Módulo VI- O Estágio supervisionado.

No processo de preparação do Curso ABEPSS Itinerante, foi sugerido, pelos docentes participantes do mesmo, que o Módulo I -"Transformações societárias e o projeto de formação profissional do serviço social: desafios para a implantação das DC"incorporasse a reflexão sobre o ensino da prática na formação profissional, tendo em vista a compreensão de que esse ensino constitui-se em um dos princípios desse projeto de formação.

4 Este Projeto foi implementado na Gestão 2011-2012 da ABEPSS, em parceria com o conjunto CFESS-CRESS. Para maiores detalhes, ver o projeto na sessão "Documentos" deste número da Revista. 
Finalizando o curso, os participantes fizeram uma avaliação, através de um roteiro com questões específicas de cada módulo. Esse roteiro, após respondido, foi entregue às vice-presidentes da ABEPSS que elaboraram um relatório final do projeto. Esse relatório não seguiu um mesmo padrão por todas as regionais. Assim, há relatórios que expressam as respostas individuais dos participantes e por turma, bem como, relatórios que trazem as respostas de forma geral, contendo o relato de todas as turmas I grupos e outros que trazem o resultado por turma / grupostendo em vista que as regiões da ABEPSS desenvolveram o curso em mais de uma turma / grupo ${ }^{5}-\mathrm{e}$, ainda, duas regionais apresentaram o relatório de forma sucinta, sem conter as avaliações por módulos, o que nos impediu de tratá-los aqui.

Dessa forma, os dados aqui apresentados constituem-se de uma análise preliminar das avaliações registradas nos relatórios finais do projeto ABEPSS itinerante no que se refere ao Módulo I - Transformações societárias e o projeto de formação profissional do serviço social, onde foi tratado o ensino da prática. Neste módulo, duas questões foram específicas a esse item e são referências para este artigo: Quais as estratégias do curso para garantir um ensino teórico-prático em todo o currículo?Quais os componentes curriculares que tratam diretamente dos procedimentos operacionais da prática profissional?Priorizamos, aqui, trabalhar as respostas dessas duas questões, tomando como referência os dados fornecidos nos relatórios das quatro regiões da ABEPSSque apresentaram o relatório mais descritivo: Norte, Centro-Oeste, Leste e Sul I.

Ressaltamos que apresentaremos, apenas, uma exposição do debate a partir das duas questões elencadas acima, uma vez que a não padronização dos relatórios não permitiram uma análise quantitativa do mesmo.

No que se refere à primeira questão contida no roteiro estratégias do curso para garantir um ensino teórico-prático em todo curso - fundamentadas nos preceitos explicitados nas partes anteriores deste artigo, verificamos duas tendências na

5 As regiões Norte, Nordeste, Centro Oeste e Sul II organizaram duas turmas ou grupos, já as regiões Sul I e Leste organizaram três turmas ou grupos. 
compreensão e trato do ensino da prática, hoje, na formação profissional do Assistente Social brasileiro.

A primeira tendência - que não é majoritária, mas, presente em todas as regiões -, é a existência de clareza por parte de algumas unidades de Formação Acadêmicas (UFA) de ser o ensino da prática em nossa formação um ensino teórico-prático e, dessa forma, reconhecem que este perpassa todo o curso, ou seja, há uma compreensão de que todos os componentes curriculares constituem-se de conteúdos teórico-práticos.

Essa tendência evidencia-se ao afirmarem que essa relação ocorre por meio de todos os componentes curriculares: disciplinas, seminários temáticos, atividades complementares, monitoria, estágio curricular, pesquisa e extensão. Não se trata de assegurar momentos pontuais na formação para a reflexão da prática, mas de compreender o movimento teoria-prática que ocorre ao longo da formação profissional, mesmo que alguns componentes curriculares tratem mais especificamente da ação profissional e dos conhecimentos procedimentais.Vejamos os relatos abaixo:

[ O ensino da prática ocorre] Em todos os componentes curriculares constitutivos do Projeto Pedagógico do Curso procurando sempre demonstrar a diferença de identidade e a unidade existente e indissociável entre teoria/prática, além de termos uma disciplina específica que traz esta discussão que é Instrumentalidade em Serviço Social, a qual as duas primeiras unidades são a questão filosófica e teórico-metodológica da instrumentalidade e na última unidade abordamos os instrumentais (Relatório ABEPSS itinerante-Leste, 2012 - digitado).

[...] todas as disciplinas se esforçam para materializar seu objeto de estudo, sem realizar uma dicotomia entre teoria e prática, todavia, o departamento de Política Social e Serviço Social Aplicado e suas disciplinas possui ênfase no eixo de conhecimento teórico-prático que está incluso no quarto eixo do Currículo, que se referem à Processos Políticos, Políticas Sociais, Planejamento e Administração (Relatório ABEPSS itinerante-Leste, 2012 - digitado). 
[...] o ensino teórico-prático é contemplado nas disciplinas de questão social, de política social, pesquisa, ética, serviço social e processo de trabalho, supervisão acadêmica. Ressalta-se a importância de oficinas, seminários temáticos e atividades complementares para a materialização do ensino teórico-prático(Relatório ABEPSS itinerante-NOrte, 2012, p. 41 - digitado).

Busca-se um ensino integralizador abarcando toda a complexidade da vida cotidiana e das relações que se apresentam na realidade na qual os assistentes sociais se defrontam em seu cotidiano profissional (Relatório ABEPSS itinerante - Sul I, 2012, p.12).

Os relatos indicam uma clareza no trato do ensino da prática, ou seja, entende-se que os conhecimentos teóricos são reprodução ideal do movimento real e como tal são fundamentais, uma vez que oferecem conhecimentos sobre as expressões da questão social, objeto de trabalho dos Assistentes Sociais. Igualmente, reconhece-se que a formação profissional requer diferentes tipos de conhecimentos, dentre eles, o teórico e o procedimental.Portanto, são necessários componentes curriculares que tratem, também, do ensino deste último. A citação a seguir vai ao encontro dessa afirmativa:

No geral, em todos os 3 núcleos há um esforço de articular a teoria com a prática profissional, sendo mais efetivo nas disciplinas de processo de trabalho, nas oficinas, seminários temáticos, administração e planejamento em SS, ética profissional e pesquisa em SS (Relatório ABEPSS Itinerante Norte, 2012, p. 43 - digitado).

Esse entendimento deixa explícito que não há um distanciamento entre teoria e prática. Contudo pode haver, na formação, uma ausência ou poucos componentes curriculares que tratem dos conhecimentos procedimentais, técnico-operativos, éticos, necessários à mediação entre conhecimento teórico e intervenção profissional, em detrimento dos componentes que tratam mais dos conhecimentos teóricos.

A segunda tendência- majoritária nos relatos - é o contraponto da primeira. Há uma concepção de separação entre ensino 
teórico e ensino da prática e uma concepção de similitude entre ensino da prática e conhecimentos procedimentais, associando o ensino da prática, exclusivamente, aos componentes curriculares que tratam dos procedimentos, instrumentais técnico-operativos da intervenção. Essa tendência é visualizada nas afirmativas abaixo.

Em todos os semestres em várias disciplinas existe uma carga horária prática com a finalidade do docente realizar atividades planejadas (teórico-práticas) tais como: visitas técnicas, aulas de campo. Além da articulação permanente teórico prática nos conteúdos disciplinares (Relatório ABEPSS Itinerante Norte, 2012, p. 41-digitado).

há iniciativas de articulação teoria-prática: por meio das disciplinas de Trabalho (organizações e instituições, movimentos sociais e famílias), de Estágio e Supervisão Acadêmica e os projetos e atividades de extensão desenvolvidos pelos núcleos de pesquisas (Relatório ABEPSS Itinerante Leste, 2012 - digitado).

muitas vezes se garante na ementa essa relação teoria-prática, mas, não há uma discussão e acompanhamento dos colegiados do curso (Relatório ABEPSS Itinerante Leste, 2012 - digitado).

O curso desenvolve pelo menos três iniciativas de articulação teoria-prática: as disciplinas de Processos de Trabalho (organizações e instituições, movimentos sociais e famílias), as disciplinas de Estágio e Supervisão Acadêmica, as visitas de campo à instituições e os projetos e atividades de extensão desenvolvidos pelos núcleos de pesquisa(Relatório ABEPSS itinerante - Sul I, 2012, p.12).

Os relatos acima mostram que não há um entendimento de que o ensino da prática perpassa todo o currículo. Ou seja, conforme dito anteriormente, relaciona-se o ensino da prática, apenas, com conhecimentos do âmbito da prática profissional: procedimentais, instrumentais, etc. Por outro lado, parece que, na verdade, o que estão sentindo falta é de componentes curriculares que tratem mais dos conhecimentos operacionais, conforme citação abaixo: 
Percebe-se uma tendência maior no curso ao ensino teórico, ainda que exista um esforço de articular teoria e prática, o que exige uma profunda e consistente apropriação do método, e algumas experiências acontecem, mas essa questão é um desafio a ser enfrentado cotidianamente (Relatório ABEPSS Itinerante Leste, 2012 - digitado).

De outro modo, nas respostas à segunda questão(quaisos componentes curriculares que tratam diretamente dos procedimentos operacionais da prática profissional?), vimos que foram indicados vários componentes curriculares. Apenas uma resposta refere-se somente a um componente curricular, como podemos ver:

Projetos Comunitários, Questão Social, Oficina II- Instrumentos e técnicas em Serviço Social, Planejamento em Serviço Social, Política Social, Ética Profissional, Direito e Legislação, Gestão em Serviço Social, Seguridade Social, Pesquisa em Serviço Social, Oficina IV - Formação Profissional;Estágio Supervisionado I e II, Trabalho de Conclusão de Curso (Relatório ABEPSS itinerante - Sul I, 2012, p.14).

Disciplinas do núcleo de fundamentos do trabaIho profissional, o Estágio, Oficina de Formação Profissional, Introdução ao Estágio Supervisionado, Estágio Supervisionado em Serviço Social I, II e III, Seminário de Fundamentação da Prática Profissional (Relatório ABEPSS itinerante, Região Centro-oeste, 2012 - digitado).

"Planejamento e Projeto", “Avaliação e Monitoramento", "Instrumentalidade e Serviço Social", "Técnicas de Intervenção" e ainda "Orientação e Treinamento Profissional" (OTP). Todas elas são consideradas disciplinas obrigatórias e que tratam diretamente dos procedimentos operacionais da prática profissional. Todavia, a disciplina de OTP deve ser feita de acordo com a área de estágio em que se insere o aluno (Relatório ABEPSS Itinerante Leste, 2012 - digitado).

[...] em outros casos há a localização dessa dimensão focada essencialmente na disciplina de Estágio 
Supervisionado (Relatório ABEPSS itinerante,

Região Centro-oeste, 2012 - digitado).

O estágio supervisionado é apontado em todos os relatórios como um dos componentes que tratam desse conhecimento, entretanto, não é apontado como o único. A ele, são acrescidos mais componentes, tais como, oficinas, laboratórios.

\section{CONSIDERAÇÕES FINAIS}

Os relatórios trazem elementos importantes para pensarmos a formação profissional do Assistente Social hoje ${ }^{6}$. Eles mostram um processo de apreensão das Diretrizes Gerais para os Cursos de Serviço Social que mesclam avanços e continuidades.

Tendo por base o resultado da Pesquisa "Estado da Arte sobre as Diretrizes Curriculares de 1996", desenvolvida pela ABEPSS, nas gestões 2005/2006 e 2007/2008, no que diz respeito ao eixo "ensino da prática", esse avanço se expressa em dois aspectos: o fato do estágio supervisionado não ser mais considerado como o único "espaço do ensino da prática" e, igualmente, não ser tratado como o único espaço para o tratamento dos conhecimentos de ordem procedimental, conforme constatado na referida pesquisa,

Na análise dos dados produzidos na pesquisa, foram detectadas as seguintes tendências sobre o estágio curricular: o estágio constitui-se na principal ação na qual materializam-se os pressupostos das discussões sobre o tratamento dispensado à prática, ou seja, em que esse conteúdo ganha especificidade, na formação profissional (RAMOS, 2007, p. 160-161).

Os relatórios, conforme visto acima, mostram que este conteúdo vem sendo, atualmente, pulverizado em outros componentes curriculares. Entretanto, vimos, ainda,uma dificuldade na compreensão de transversalidade do ensino da prática, ainda que essa compreensão se mescle com concepções que trabalham corretamente essa relação. Essa constatação foi, também, apontada por Ramos ao afirmar as dificuldades referentes ao tratamento

6 O trato desses relatórios e roteiro de avaliação do Projeto ABEPSS itinerante merecem um estudo mais cuidadoso e aprofundado, o que não foi possível neste momento e não se tratava do objetivo deste artigo. 
do ensino da prática: “Aqui aparece a clara distinção positivista entre disciplinas teóricas e disciplinas práticas [...]” (RAMOS, 2007, p. 167).

Ainda, como avanço, é importante destacar que a tendência que trata o ensino da prática como transversal a todo o currículo salienta a existência de diferentes tipos de conhecimentos, os quais devem ser contemplados na formação. Reforça, igualmente, a necessidade de uma maior aproximação entre os conhecimentos obtidos na academia e a realidade dos diferentes mercado de trabalho onde se inserem os Assistentes Sociais e os estagiários. Percebem, por parte dos docentes e supervisores de campo, certo distanciamento, como também, entre os espaços sociocupacionais e as Unidades de Formação Acadêmica (UFA). Aqui eles situam o problema na questão correta: ou seja, o problema não está em um "suposto e equivocado" distanciamento entre ensino teórico e ensino prático, mas, sim, em um distanciamento entre conhecimentos sobre o mercado de trabalho e conhecimentos adquiridos na academia; afastamento entre assistentes sociais da intervenção e academia.

Nessa direção, alguns participantes apontaram a necessidade de uma maior articulação entre formação e mercado de trabalho profissional, como forma de atender a multiplicidade de questões inerentes aos espaços sociocupacionais que rebatem na formação profissional. Indicam que esse afastamento pode ser minimizado através do estágio curricular. Também reafirmam que este é um espaço privilegiado de aproximação entre espaço sócio-ocupacional e academia. Mas não somente isso: a pesquisa e a extensão são, igualmente, espaços que possibilitam essa articulação, desde que devidamente ocupados. Neste sentido, o Fórum de Supervisão de Estágio é indicado como uma possibilidade de formação permanente, envolvendo docentes, supervisores e discentes, bem como, instituição de ensino e instituição campo de estágio, possibilitando a articulação academia / campo de estágio, conforme orientação da Política Nacional de Estágio - PNE (2009). É nessa direção que o estágio é um componente fundamental em nossa formação profissional. 
Enfim, os relatórios indicam uma inquietação por parte dos participantes e unidades de formação e a busca de estratégias para romperem com os desafios postos ao pleno desenvolvimento dos princípios, diretrizes e fundamentos teóricos, éticos e políticos que norteiam o projeto de profissão expresso nas diretrizes curriculares de 1996.

\section{REFERÊNCIAS}

ASSOCIAÇÃO BRASILEIRA DE ENSINO EM SERVIÇO SOCIAL ABESS. Centro de Documentação e Pesquisa em Política Social e Serviço Social - CEDEPSS. Diretrizes gerais para o curso de Serviço Social. Cadernos ABESS, São Paulo: Cortez, n. 7, p. 58-76, 1997.

.Proposta Básica para o projeto de formação profissional. Revista Serviço Social e Sociedade, São Paulo: Cortez Editora, n. 50, p. 143-171, 1996.

- Política Nacional de Estágio. 2010. Disponível em <http:www.abepss.org.br>. Acesso em: 23 jan. 2013.

.ABEPSS Itinerante: as diretrizes curriculares e o projeto de formação:brochura para o curso de atualização. Brasília: ABEPSS, 2012.

. Relatório do Curso ABEPSS Itinerante, Região Sul I. 2012. Documento digitado.

. Relatório do Curso ABEPSS Itinerante, Região Sul II.2012. Documento digitado.

. Relatório do Curso ABEPSS Itinerante, Região Leste.2012. Documento digitado.

- Relatório do Curso ABEPSS Itinerante, Região CentroOeste.2012. Documento digitado.

- Relatório do Curso ABEPSS Itinerante, Região Norte. 2012. Documento digitado. 
. Relatório do Curso ABEPSS Itinerante, Região Nordeste. 2012. Documento. digitado.

BOSCHETTI,I.S. O Desenho das Diretrizes Curriculares e Dificuldades na sua Implementação. Revista Temporalis, ano IV, n.8, p. 17-30, 2004.

CASSAB, M. A. Indicações para uma Agenda de Debates sobre o Ensino da Prática. Revista Temporalis,Brasília: ABEPSS, v.1, n.2, 2000.

CONSELHO FEDERAL DE SERVIÇO SOCIAL - CFESS. Resolução n. 533, de 29 de setembro de 2008. Disponível em <http:www.cfess. org.br>. Acesso em: 23 jan. 2013.

FORTI, V.; GUERRA, Y. Serviço Social: Temas, Textos e Contextos. Rio de Janeiro: Editora Lúmen Júris, 2010.

NETTO, J.P. Transformações societárias e Serviço Social - notas para uma análise prospectiva da profissão. Revista Serviço Social e Sociedade, São Paulo: Cortez Editora, n. 50, p. 87-132, abr. 1996.

RAMOS, S. R.A Prática na Formação Profissional em Serviço Social:tendências e dificuldades. Revista Temporalis, Brasília: ABEPSS,v. 1, n. 14, 2007.

SANTOS, C. M. dos. Os Instrumentos e Técnicas: Mitos e Dilemas na Formação Profissional do Assistente Social no Brasil. Tese (Doutorado) - Escola de Serviço Social da Universidade Federal do Rio de Janeiro, Rio de Janeiro, 2006.

. Na Prática a Teoria é Outra? Mitos e Dilemas na Relação entre Teoria, Prática, Instrumentos e Técnicas no Serviço Social. Rio de Janeiro: Lumen Juris, 2010. p. 71-89.

SANTOS, C.M.; ABREU, M.H.E. Desafios do Estágio Supervisionado na Atualidade.PEREIRA, L. D.; ALMEIDA, N.L.T de. Serviço Social e Educação. Rio de Janeiro: Lumen Juris, 2012. Coletânea Nova de Serviço Social. 